\title{
What can we learn from Covid-19 pandemic's impact on human behaviour? The case of France's lockdown
}

\author{
Cyril Atkinson-Clement (10 ${ }^{1,3 凶}$ \& Eléonore Pigalle (10) ${ }^{2,3}$
}

Year 2020 will mark History, with the emergence of the new Covid-19 virus, and more importantly, the consequent political decisions to apply freedom restriction at such a largescale. Identifying the human behaviours during this extraordinary period represents a unique opportunity to both improve our fundamental knowledge and to improve future management of similar issues. Throughout almost all the duration of the French lockdown (from March 24, 2020 to May 10, 2020), we carried out an online survey on more than 12,000 individuals well distributed over the country. This online survey was performed by using both LimeSurvey and Google Forms services and was addressed to adults living in France. Statistical analyses combined classical inferential approach, mapping, clustering and text mining. The results showed that a significant part of the population moved out just before the lockdown (around 10\% of our sample) and we highlighted three different profiles of participants. The results emphasised that the lockdown measures compliance was lower in two cases: (i) an unfavourable living environment (referring to social and economic inequity) associated with a high feeling of fear and a lack of trust towards Governmental measures; or (ii) the feeling that the risk was low due to the fact that others complied with the measures. In case a similar situation should occur again, it is recommended that Governments broadcast clear speeches to improve trust, limit fear and increase cooperative behaviours.

\footnotetext{
${ }^{1}$ Sorbonne Université, Institut du Cerveau - Paris Brain Institute - ICM, Inserm, CNRS, AP-HP, Hôpital de la Pitié Salpêtrière (DMU 6), Paris, France. ${ }^{2}$ Laboratoire Ville Mobilité Transports UMRT9403, Gustave Eiffel - ENPC, 77455 Marne-la-Vallée cedex 2, France. ${ }^{3}$ These authors contributed equally: Cyril

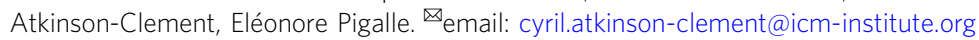




\section{Introduction}

he Covid-19 health crisis is a first of a kind situation at every field. Never before in contemporary world's History, a similar situation had occurred, leading to strong political decisions consisting of restricting human interactions through a total quarantine, named lockdown. Even if quarantine effects had already been studied (Brooks et al., 2020), never a similar lockdown was applied, with a comparable duration (in general they never lasted more than 10-15 days) and at a such scale (several countries simultaneously). Moreover, added to its biological characteristics, like any viral epidemic, the Covid-19 created also a social crisis, which spread essentially due to human behaviours, to individual perception of the situation and to our decisionmakings (Pullano et al., 2020). In this context, Human and Social Sciences give a unique opportunity to retrospectively understand individual decisions and prospectively improve our future human management strategies (Bavel et al., 2020; Brooks et al., 2020; Habersaat et al., 2020). Moreover, pending a vaccine or a specific treatment, only behavioural measures were highlighted as efficient to reduce the virus transmission, such as physical distancing, face masks and eye protection (Chu et al., 2020), which even could remove the need for a lockdown (López and Rodó, 2020). Therefore, obtaining individuals' compliance to several recommendations represents a public health objective (Lewnard and Lo, 2020, p. 19; Sheikh et al., 2020).

Based on both previous epidemic issues and the past months regarding the Covid-19 (even if studies were not always peerreviewed), some lessons could be learnt regarding human behaviours. For instance, protective measures are much more respected by women, old people, individuals with high anxiety and individuals with high Government trust (Bish and Michie, 2010; Storopoli et al., 2020). Regarding the perception of the situation, fear of the virus (Harper et al., 2020), self-estimated vulnerability (risk to be infected (Shinan-Altman and Levkovich, 2020; van der Pligt, 1996; Xu and Peng, 2015)) and risk to develop a severe form (Bish and Michie, 2010) increases the probability to apply Governmental recommendations. In addition, this risk estimation is based on self-vulnerability rather than on the probability to infect others at-risk persons (Wise et al., 2020), and interestingly, individuals very often made the basic mistake consisting of perceiving oneself as less at risk than others (van der Pligt, 1996). Even more, risk perception could be modulated using Governmental media, leading to increased self-protective behaviours (Duan et al., 2020; Everett et al., 2020). A recent study highlighted that compliance to Governmental measures was especially linked with health beliefs (Clark et al., 2020), reinforcing the conclusion that measures acceptation depends more of situation perception than of pre-existing dispositions (Zajenkowski et al., 2020). In conclusion, all these facts point out that risk perception is definitely a central element of public communication (Reynolds and Seeger, 2005).

Therefore, based upon an important online survey $(n=12,064)$ started one week after the beginning of the total lockdown in France, and stopped on the last day of the lockdown (key dates, daily deaths and spatial deaths distribution are reported in the Fig. 1a, b), our main aim is to identify the individual's characteristics and situation perceptions that lead to respect the Governmental measures. To the best of our knowledge, our study is one of the first to provide empirical data on human behaviours captured during the lockdown, at a national scale.

\section{Methods}

Design and participants. This online survey was conducted from March 24, 2020 to May 10, 2020, corresponding to the beginning of the second week of the first lockdown and to its last day. We applied no restriction on age, gender, professional situations, education level or other variable. The instruction only mentioned that the online survey was more adapted to adults living in France. The online survey was broadcast as widely as possible, through professional and personal networks, mailing list of associations, political parties, companies and newspapers, suggesting to share the online survey with their own personal and professional networks. The online survey mainly focused on demography, occupations, mobility and life habits, social perception, usual residency and their residency during the lockdown, lockdown perception, feelings and willingness to change behaviours after the Covid-19 period. Several data were removed such as incomplete data (not recorded), under age $18(n=153)$ and people not living in metropolitan France (i.e. Guadeloupe, Martinique, French Guiana, Réunion, Mayotte, Saint-Pierre and Miquelon, Saint-Barthélemy, Saint-Martin, Wallis and Futuna, French Polynesia, New Caledonia, French Southern and Antarctic Lands) or who lived in another country during the lockdown $(n=241)$ to avoid important spatial and social differences.

The survey was carried out electronically with the LimeSurvey services during the first week, then with the Google Forms to increase access and remove limitations on number of participants. The participants identification was not possible, through both the web services and the obtained data. Our study complies with ethical standards of the relevant national and institutional committees on human experimentation. Before starting the online survey, a statement was presented to the participant, indicating that the data collected through the survey will remain confidential and anonymous and could be used for scientific publications.

French key dates. Regarding the French context, all the decisions that have been taken were simultaneously and homogeneously applied to all the country. The key dates were as followed (Fig. 1a): on January 24, the three first European cases were identified in France; on January 31, 220 French citizens were repatriated from China; on February 14, the first out-Asia death due to the Covid-19 was declared in France for an imported case; on February 26, the first French death due to the Covid-19 was declared; on March 5, the first Governmental rule appeared with the prohibition of grouping of more than 5000 individuals; on March 8, groupings of more than 1000 individuals were forbidden; the 11 March 2020, visits in retirement homes were forbidden; the 12 March 2020, first discourse of the President Macron announcing the close of all study places, but keeping the local elections; on March 13, grouping of more than 100 individuals were forbidden; on March 14, all non-essential places and stores were closed until further notice; on March 15, local elections recorded the highest abstention rate ever recorded; on March 6, President Macron gave his second speech comparing the situation to a "health war" and announcing the general lockdown from March 17 at 12 a.m.; it was planned to last two weeks, with a $135 €$ fine in case of nonrespect and the need to fulfil a certificate justifying any trip; on March 23, an emergency health law increasing the Governmental power to restrict population movement rights was voted; on March 24, the level of 1000 deaths due to the Covid-19 was reached; on March 27, the lockdown was extended until at least April 15; on April 3, the level of 5000 deaths due to the Covid-19 was reached; on April 8, the level of 10,000 deaths due to the Covid-19 was reached; on April 13, President Macron carried out his third speech, announcing that the lockdown was extended to May 11; on April 19, the Government started to talk about the lockdown's end; on April 20, the level of 20,000 deaths due to the Covid-19 was reached; on April 28, the Government continued to 


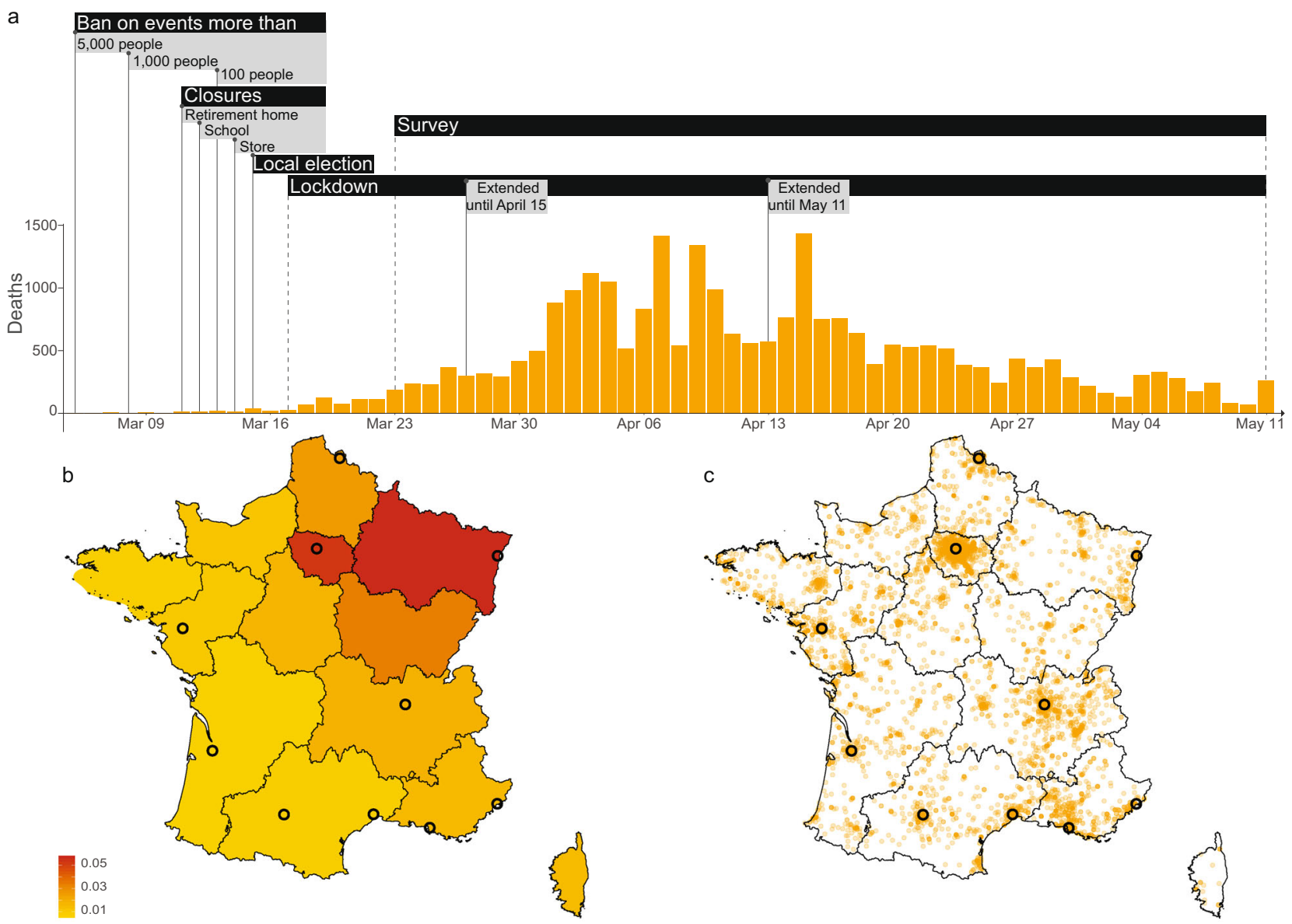

Fig. 1 French context of the Covid-19 until the last lockdown day. Part a reports the key dates (top panel) and the officially reported daily deaths due to the Covid-19 (bottom panel). Part $\mathbf{b}$ represents the percentage of the regional population who died due to the Covid-19. Part $\mathbf{c}$ represents the residency position for all our participants.

precise the conditions of the end of the lockdown, with an authorisation to travel within a radius of $100 \mathrm{~km}$; on May 7, the date of the lockdown's end planned for the 11 May was confirmed; the 11 May 2020, the general lockdown was put to an end.

Statistics. All statistics were carried out with the $\mathrm{R}$ software (R Core Team, 2013). Inferential statistics implied Chi-squared for $2 \times 2$ contingency tables, ANOVA for numerical variables, partial binomial multiple regressions for bivariate variables and partial multinomial logistic regression for categorial variables. Partial models implied to insert several predictors in the same model to control every effect according to the others, and thus to control for bias. All results were associated with Cohen's $d$ effect size. Cohen's $d$ could be interpreted as very small $(d>0.01)$, small $(d>0.2)$, medium $(d>0.5)$, large $(d>0.8)$, very large $(d>1.2)$ or huge $(d>2$ (Cohen, 2013; Sawilowsky, 2009)). All multiple comparisons were corrected using the Bonferroni approach to avoid incorrect null hypothesis rejection. Significant threshold was fixed at $p \leq 0.05$.

Clustering was performed using the k-means method. To identify the optimal number of clusters, we computed models' comparisons from 2 to 10 clusters using 24 statistics (Ball and Hall, 1965; Beale, 1969; Calinski and Harabasz, 1974; Davies and Bouldin, 1979; Duda and Hart, 1973; Dunn, 1974; Friedman and Rubin, 1967; Halkidi et al., 2000; Halkidi and Vazirgiannis, 2001; Hartigan, 1975; Hubert and Levin, 1976; Krzanowski and Lai, 1988; Marriott, 1971; McClain and Rao, 1975; Milligan, 1980; Milligan and Cooper, 1985; Ratkowsky and Lance, 1978;
Rousseeuw, 1987; Sarle, 1983; Scott and Symons, 1971; Tibshirani et al., 2001) and selected the median number of optimal models reported by the statistics using Euclidean distance. Details of the output statistics are available in the Fig. S1. The k-means clustering apply by steps: (i) select as many individuals as mentioned in the model (in our case, 3); (ii) each of them is associated with the closest individual to generate a temporary cluster; (iii) the gravity centre of the new temporary cluster is calculated and become the new centre; (iv) each observation is reallocated to the cluster; ( $v$ ) the procedure continued until convergence. All the details of the procedure are described in the following publication related to the $\mathrm{R}$ package NbClust (Charrad et al., 2014).

Last, text mining was performed on a free answer ("Does the lockdown impact your life:" ["positively"; "negatively"; "no change"], "Could you develop?"). The corpus was cleaned by removing capital letters, additional white spaces, removing numbers, punctuations, and basic words (e.g. "the", "and", "but", "or"). Then, the frequency of each word was calculated for each cluster and compared between them using a variation coefficient (VC). For each cluster, 20 words with the highest VC and probability to be used were considered as specific.

\section{Results}

Sample description. Our sample involved 12,064 individuals. When we compared weeks, we found an unbalanced distribution of ages $(d=0.878)$, socio-professional categories $(d=0.865)$, regions of residency $(d=0.56)$, education levels $(d=0.504)$, 
home compositions $(d=0.439)$, gender $(d=0.359)$, types of residency $(d=0.312)$, and perceived salaries $(d=0.153)$. The sample characteristics by week are available in Table 1 and their spatial distribution is available in Fig. 1c.

Behaviours right before the lockdown. In the days/hours preceding the lockdown, we noted that $11.7 \%$ of our participants declared having changed of usual place residence. The reasons were, first to be the closest possible to a family member or a friend (76.7\%), for the quality of the living environment (59.6\%), to increase the living place area $(48 \%)$, to avoid over-population (20.1\%) and for an unexpected reason (4.7\%). Distance between the original and the lockdown residencies is represented in Fig. 2a.

Regarding the distance from their usual place of residence, $13.9 \%$ remained in the same city, $14.9 \%$ in the same department, $19.7 \%$ in the same region and $51.4 \%$ further away. Interestingly, most of the residence changing were from one type of residency to the same $(X=35.7 ; p<0.0001 ; d=0.318$; Fig. $2 b)$. Especially, we found that those who live in suburban areas mainly moved to another suburban home $(p=0.0014)$, as well as those living in the countryside $(p<0.0001)$. This was not the case for people living in a flat, who represented the most important proportion of people leaving their home (81.1\%).

Partial logistic regression highlights that the probability to change of residence before the lockdown was significantly predicted by the familial organisation $\left(F_{(5 ; 12020)}=51.392 ; p<\right.$ $0.0001 ; d=0.298$; higher for people living in collocation or alone with no child), professional situation $\left(F_{(10 ; 12020)}=12.98 ; p<\right.$ $0.0001 ; d=0.208$; higher for students, retired people and people with no job), age $\left(F_{(1 ; 12020)}=118.034 ; p<0.0001 ; d=0.198\right.$; slope $=-0.044)$, residency type $\left(F_{(2 ; 12020)}=52.152 ; p<0.0001\right.$; $d=0.186$; higher for people living in flats inside the city), perceived salary $\left(F_{(4 ; 12020)}=6.9536 ; p<0.0001 ; d=0.096\right.$; higher for people judging their life as very comfortable) and the gender $\left(F_{(1 ; 12020)}=6.447 ; p=0.011 ; d=0.046\right.$; higher for women $)$. No significant association was found according to the region of residency $\left(F_{(12 ; 12020)}=1.1535 ; p=0.311 ; d=0.068\right)$ or education level $\left(F_{(6 ; 12020)}=1.894 ; p=0.078 ; d=0.061\right)$.

Perceived situation throughout the lockdown duration. To identify the lockdown perception, we generate k-means clustering on the basis of several sentences and feelings related to the situation (Fig. 3a and Table 2). Algorithms comparisons highlighted that generating three clusters was optimal (see Supplementary Fig. 1). The first cluster (30.8\% of our sample) seems to both have positively appreciated the lockdown period and to be concerned about the pandemic crisis. The second cluster $(33.8 \%$ of our sample) can be characterised as more pessimistic, worried, stressed out, and less in agreement with Governmental measures and respect of rules. The third cluster ( $35.4 \%$ of our sample) seems not to be affected by the situation, hence not worried for itself or close relations. Throughout the course of these three profiles (Fig. 3b), we observed a decreased proportion of the cluster $1\left(F_{(1 ; 12062)}=45.449 ; p<0.0001 ; d=0.123\right)$, an increased proportion of the cluster $2 \quad\left(F_{(1 ; 12062)}=32.766 ; p<0.0001\right.$; $d=0.104)$, and no change for the cluster $3\left(F_{(1 ; 12062)}=0.6177\right.$; $p=0.43 ; d=0.014)$.

Regarding the clusters' comparison (Table 3), partial multinomial logistic regression highlighted significant differences on the perceived salary $(d=0.284)$, gender $(d=0.27)$, education levels $(d=0.174)$, type of residency $(d=0.129)$, home composition $(d=0.128)$, regions of residency $(d=0.123)$ socioprofessional categories $(d=0.116)$, and change of residence before the lockdown $(d=0.067)$. No effect of age was observed $(d=0.083)$.

Last, text mining highlighted discourses differences between the three clusters (Fig. 3c). The cluster 1 takes time to experience new activities (e.g. "refocus" [VC $=87.19 \%$ ], "reading" [VC $=67.13 \%$ ], "yoga" $[\mathrm{VC}=64.82 \%]$, "scrabble" $[\mathrm{VC}=56.49 \%]$, "cooking" [VC $=56.14 \%]$ ) and estimated the lockdown as a good opportunity (e.g. "best" [VC $=80.25 \%$ ], "get closer to" [VC $=74.59 \%$ ], "essential" $[\mathrm{VC}=64.24 \%]$ ). The cluster 2 referred more to negative feelings (e.g. "depression" $[\mathrm{VC}=135 \%]$, "anger" $[\mathrm{VC}=127.65 \%]$, “worry" $[\mathrm{VC}=102.19 \%]$, "boredom" [ $\mathrm{VC}=83.51 \%]$, "fear" $[\mathrm{VC}=82.12 \%]$ ) while the cluster 3 enjoyed continuing their activities in a quieter environment (e.g. "noise" [VC $=101.29 \%]$, "peaceful" $[\mathrm{VC}=62.75 \%]$, "break" [VC $=59.32 \%]$, "read" [VC $=68.46 \%]$, "gardening" [VC=62.41\%], "spring" [VC $=60.52 \%]$, "games" $[\mathrm{VC}=56.31 \%]$, “appreciate” $[\mathrm{VC}=53.44 \%]$ ).

After the lockdown, hope for a new world? Last, we investigated to know if the lockdown was perceived as a way to change habits and lifestyle in our three clusters. Using partial multinomial logistic regression, we identified that the main differences between our three clusters were for the "change the vision of others" $(X=240.78 ; \quad p<0.0001 ; d=0.282 ;$ slope Cluster $1=2.19 \%$; slope Cluster $2=1.26 \%$; slope Cluster $3=-3.45 \%)$ and "get closer from relations" $(X=214.38 ; p<0.0001 ; d=0.267$; slope Cluster $1=1.87 \%$; slope Cluster $2=0.78 \%$; slope Cluster $3=-2.66 \%)$, followed by "change my life habits" $(\mathrm{X}=48.95 ; p<$ $0.0001 ; d=0.127$; slope Cluster $1=1.36 \%$; slope Cluster $2=0.05 \%$; slope Cluster $3=-1.4 \%$ ) and "change my eating habits" $(X=28.77 ; p<0.0001 ; d=0.098$; slope Cluster $1=0.95 \%$; slope Cluster $2=-0.15 \%$; slope Cluster $3=-0.79 \%$ ). No significant effect was found for the sentence "change my travel habits" $(X=5.42 ; p=0.066 ; d=0.042$; slope Cluster $1=0.33 \%$; slope Cluster $2=0.15 \%$; slope Cluster $3=-0.48 \%$ ).

\section{Discussion}

Spatial mobility before the lockdown. Based on our online survey, several lessons on human behaviours could be obtained. First, while population movement control was already associated with a high decrease of covid-19 transmission (Bi et al., 2020; Chinazzi et al., 2020; Pullano et al., 2020; Tian et al., 2020; Wells et al., 2020; C. Zhang et al., 2020; R. Zhang et al., 2020, p. 19), we reported that more than $10 \%$ of our participants changed of residence specifically in the lockdown prevision. If almost $29 \%$ moved in proximity (same city or department), the rest of them moved further away, contributing to the virus spreading in the country (Duque-Calvache et al., 2020). Equivalent results were reported in France, from the French statistics and economic studies administration (INSEE, 2020) and by using mobile phone trajectory reconstruction (Pullano et al., 2020). In Italy, like our results, spatial mobility was found higher in both younger and older people, for people who can work from home and for people living in a non-family household (Duque-Calvache et al., 2020). This was possible since the total lockdown was announced one day before its enforcement. Even if this decision to delay the lockdown made the prognostic worst, it probably improved the lockdown acceptance by a part of the population.

Three ways to perceive the lockdown. We identified three participants profiles based on their situation perception. The first one reported the highest lockdown measures acceptance associated with, on the one hand, a significant concern about the covid-19, on the other hand, a satisfaction since the lockdown was an opportunity to re-focus on itself and relations (e.g. "refocus", "reading", "get closer to", "essential"). However, the proportion of individuals 
Table 1 Participants description for each lockdown weeks.

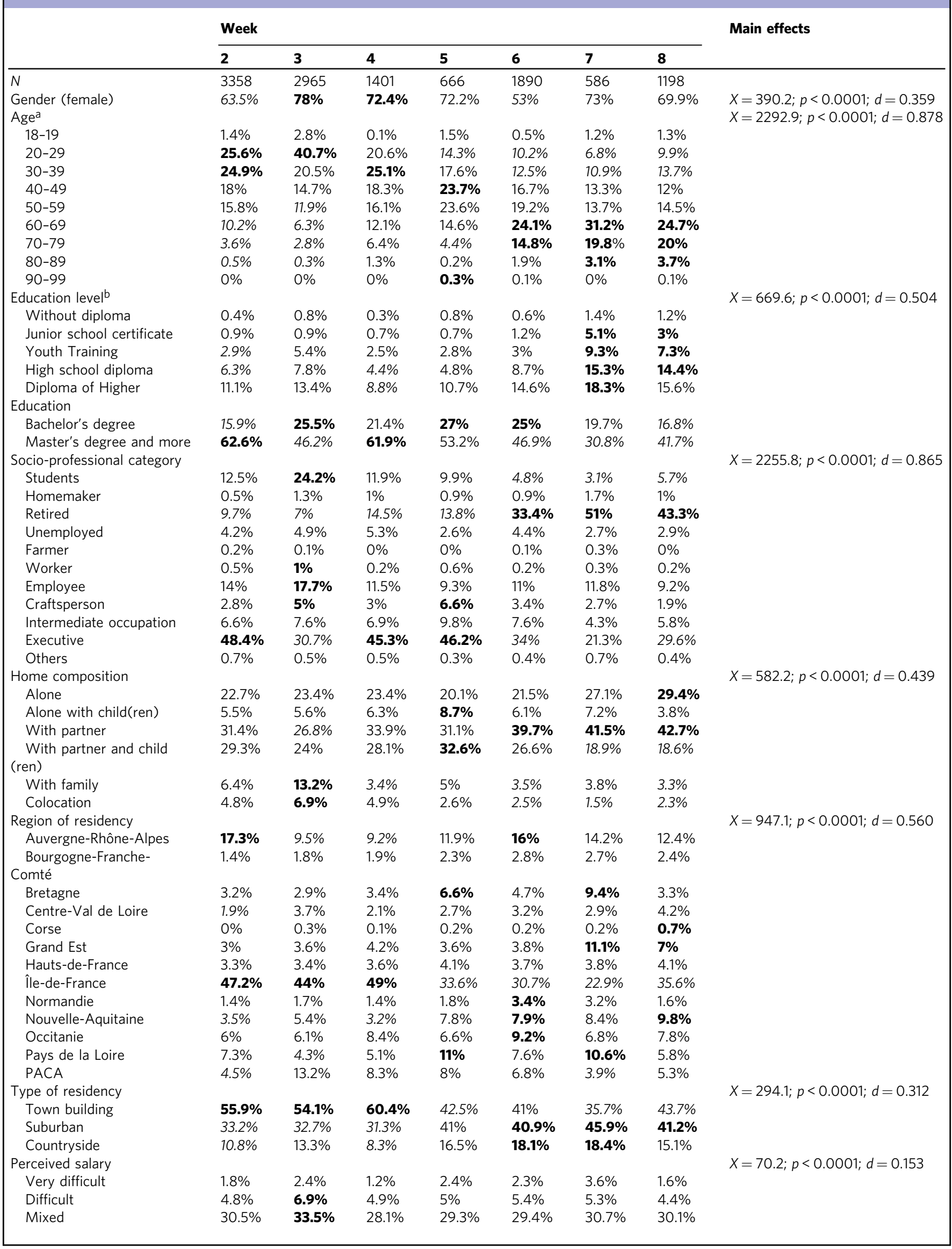


Table 1 (continued)

\begin{tabular}{|c|c|c|c|c|c|c|c|}
\hline & \multicolumn{6}{|l|}{ Week } & \multirow[t]{2}{*}{ Main effects } \\
\hline & 2 & 3 & 4 & 5 & 6 & 7 & \\
\hline Comfortable & $51.2 \%$ & $47.2 \%$ & $52.4 \%$ & $49.8 \%$ & $50.9 \%$ & $50.2 \%$ & $52.8 \%$ \\
\hline Very comfortable & $11.7 \%$ & $10.1 \%$ & $13.4 \%$ & $13.5 \%$ & $12 \%$ & $10.2 \%$ & $11.1 \%$ \\
\hline
\end{tabular}
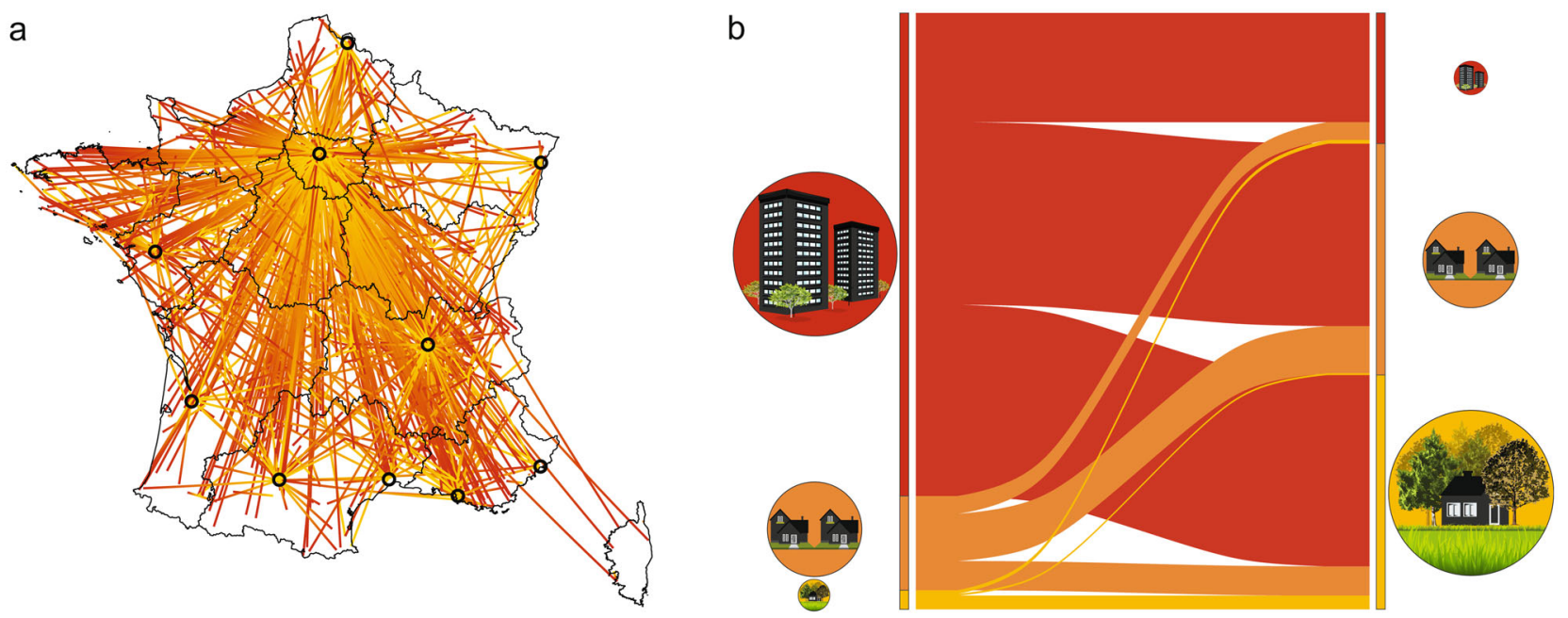

Fig. 2 Population movements during the hours preceding the lockdown. Part a represents the distance between the usual residence and the lockdown residence. The yellow part of the line represents the departure, the red part the arrival. Part $\mathbf{b}$ represents the change of residence type before the lockdown in percentage. The left part represents the usual residence and the right part the lockdown residence.

corresponding to this group decreased progressively through time. The two others tended to less apply the lockdown measures. For cluster 2 , this tendency could be explained by a perception of the situation as a punishment (i.e. "I feel like I am losing my freedom" $Z$-score $=0.528)$, even if they were highly worried by the covid-19 for themselves (i.e. "I feel safe" $Z$-score $=-0.563$ ) more than for their close relations (i.e. "I am afraid of infecting others" $Z$ score $=0.058$ ). In addition, they were the group with the lowest satisfaction regarding the Governmental measures $(Z$-score $=$ -0.333 ), a variable which was found as significantly associated with adoption of preventive behaviours (Storopoli et al., 2020). Unlike the first cluster, the proportion of our sample corresponding to this cluster progressively increased with the lockdown duration. This group corresponds to previous observations regarding frustration, boredom and sense of isolation due to quarantine (Brooks et al., 2020; Martarelli and Wolff, 2020), already identified as decreasing quarantine compliance (DiGiovanni et al., 2004; Maunder et al., 2003). The last group (cluster 3) also presented a lower measures application, but for different reasons. They reported less worried for themselves (i.e. "I feel safe" $Z$-score $=0.469$ ) and their relations (i.e. "I am worried about my close relation" $Z$-score $=-0.669)$ and estimated that the Governmental measures were enough (i.e. "I estimate that the Governmental measures are enough" $Z$-score $=0.127)$. Interestingly, if they estimated to less apply the lockdown measures (i.e. "I respect the lockdown measures" $Z$-score $=-0.053)$, they also estimated that others respected more (i.e. "I think the others respect the lockdown measures" $Z$-score $=0.134)$. These characteristics converge to the hypothesis that this group had the feeling not to be affected by the virus nor by the Governmental measures. Put together, our three groups allow us to highlight several lessons on human behaviour during this pandemic period.
The lockdown highlighted pre-existing social inequality. In the past as for during the covid-19 lockdown, several studies focused on socio-demographic predictors of measures compliance, with quite opposing results since they found (Carlucci et al., 2020; Murphy et al., 2020; Taylor et al., 2008) or not predictors (Bolarinwa et al., 2020). Our results are more in favour of an effect of the living environment, especially highlighted by the differences between the second and third clusters. For the cluster 2, we observed an overrepresentation of individuals living in Île-de-France (which includes Paris, the most expensive place in France), which perceived their purchasing power as insufficient, was more unemployed and lived in city flats. For cluster 3, we found an over-representation of highgraduate people, with comfortable quality of life, who changed of residence just before the lockdown to leave the cities, and their proportion was stable during the lockdown. Therefore, these profiles highlighted not demographics or psychological weakness, but more social and economic inequality (Bavel et al., 2020; Chung et al., 2020). This is in line with several observations that highlighted the need to especially consider people of low socio-economic status (Patel et al., 2020). Indeed, socio-economic situation contributes to increase both negative outcomes due to the situation such as loss employment or risk to develop mental health issues (Nicola et al., 2020; Patel et al., 2020; Serrano-Ripoll et al., 2020), but also risk of being infected (Holuka et al., 2020; Koh, 2020; Patel et al., 2020). This point is especially relevant and emphasises pre-existing inequality since the French Government guaranteed income (one of the most important aspects to obtain measure acceptance (Bodas and Peleg, 2020)) to the main part of the population.

Situation perception, a matter a risk valuation. However, even if clusters 2 and 3 are significantly different, they both respected less 
a

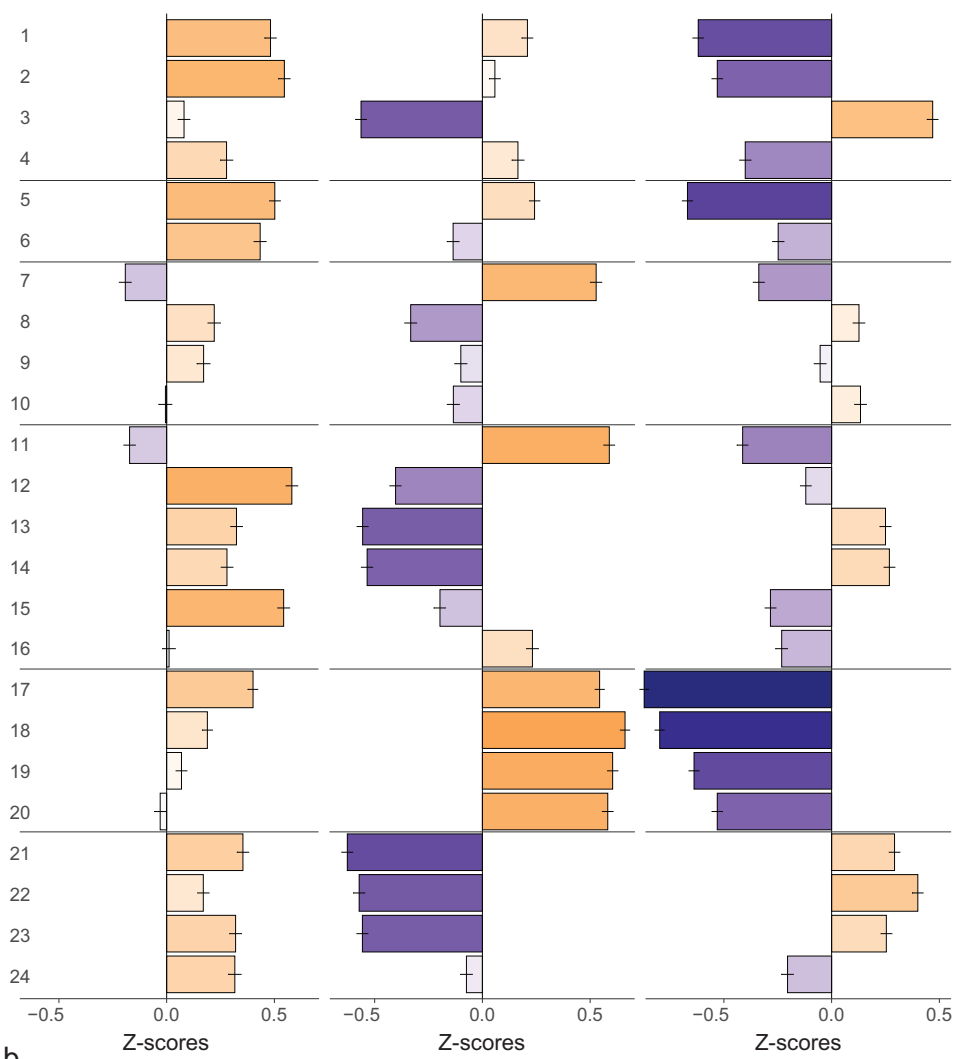

b
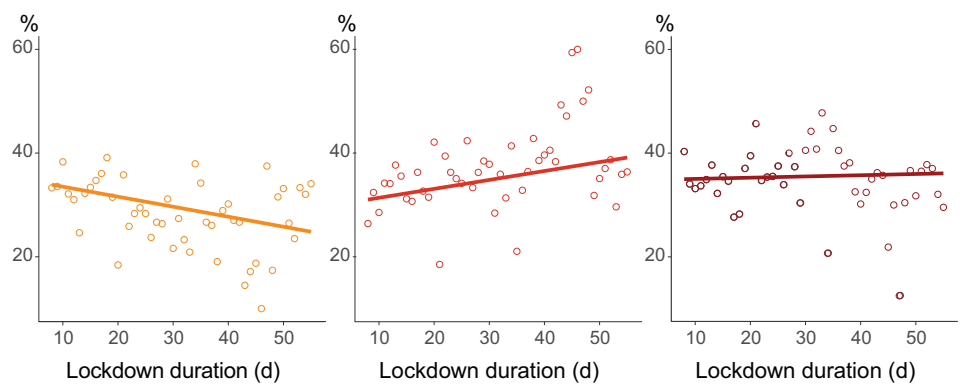

C

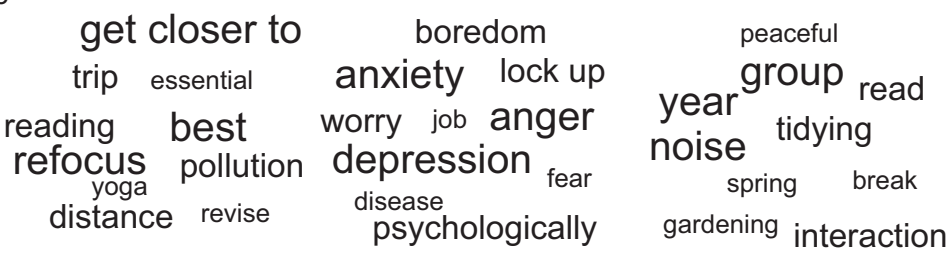

Fig. 3 Participants profiles during the lockdown. Part a represents the details of the three generated clusters of participants for the 16 sentences (1-16) and 8 feelings (17-24) used to perform k-means clustering (the details of sentences and feelings are available in the Table 2; errors bars correspond to the 95 confidence interval). Part $\mathbf{b}$ represents the proportion of participants corresponding to each cluster for all lockdown day and their tendency (significant only for clusters 1 and 2). Part $\mathbf{c}$ represents the 10 most specific words used by the three clusters.

the lockdown measures than the first cluster. We can assume that they both computed an unbalanced ratio between the perceived risk and the cost-effectiveness of the lockdown which could lead to fear, representing one of the most shared feeling during the pandemic crisis (Aslam et al., 2020). As well known, fear could lead to the highest measure compliance when they are perceived as efficient (Bavel et al., 2020; Carlucci et al., 2020; Harper et al., 2020; Witte and
Allen, 2000), representing a solution to the Covid-19 situation (Ahorsu et al., 2020). For example, risk-averse attitudes were highlighted as a relevant factor to adjust behaviours, even before Governmental measures (H. F. Chan et al., 2020; Pullano et al., 2020). However, fear is also associated with increased risky decisionmaking (Hartley and Phelps, 2012; Yang et al., 2018), which is reinforced in specific contexts of uncertainty or ambiguity (Reintjes 
Table 2 Lockdown perception for the three generated clusters.

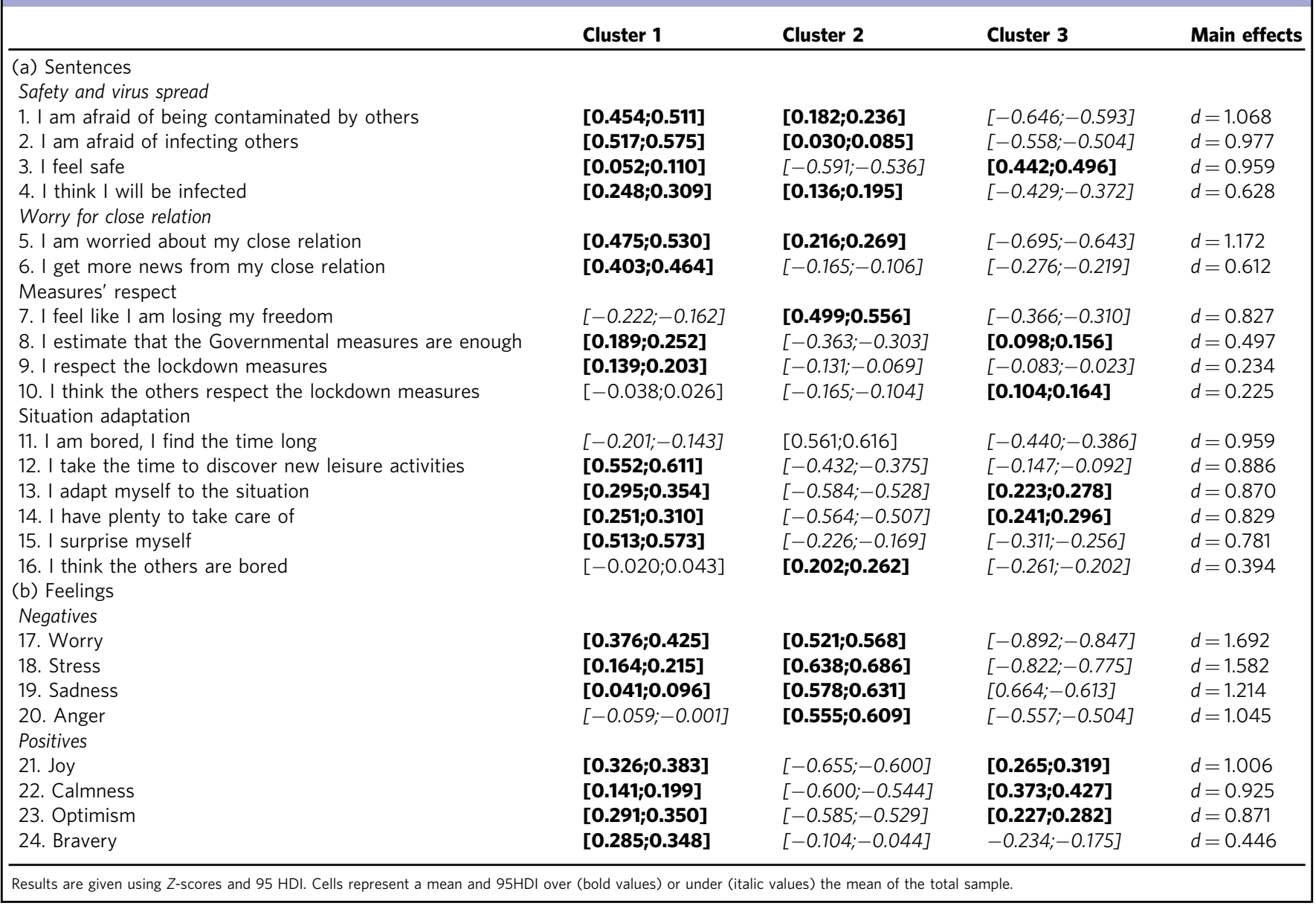

et al., 2016), such as during the lockdown period (uncertainty about the virus spreading and severity, ambiguity regarding the relevance of behavioural measures or mask wearing (Brand et al., 2007; Heilman et al., 2010)). In addition, it was reported that fear could have negative influence on preventive intentions if it was associated with collectivism (which could be the case of our cluster 2) (F. Huang et al., 2020). Therefore, in this point of view, the lack of balance between the feeling of safety (low for cluster 2, mild for cluster 1 and high for cluster 3) and the feeling that the Governmental measures are enough (low for cluster 2, mid for cluster 3 and high for cluster 1) probably contributed to the lockdown compliance (low for cluster 2, mid for cluster 3 and high for cluster 1).

For the third cluster, if low measure acceptance was, in the past, more associated to a lack of information and a feeling of isolation or exclusion from the rest of the world, these reasons are of very low probability. Like our findings, another study observed a decreased compliance in individuals with high socio-professional situations (Nivette et al., 2021). We assume that they had the feeling not to be affected since they computed as extremely weak the probability to be exposed to the covid-19 (i.e. "I think I will be infected" $Z$-score $=-0.401$ ), probability which was also decreased by the estimation that others respected the measures well (i.e "I think the others respect the lockdown measures" $Z$-score $=0.134$ ). We can explain this since most of the studies were based on specific quarantine of at-risk individuals or to restrict areas (districts or cities). Never before such an extended and unspecific lockdown was implemented, reinforcing the basic error to believe that others are more likely to be infected than oneself (Bavel et al., 2020; Sharot, 2011; Wise et al., 2020). Indeed, it was reported that total lockdown in France successfully decreased the burden on the intensive care units in the most affected regions, and prevented uncontrolled epidemics growth in the others (Cauchemez et al., 2020).

Interestingly, we also suggest that this weak infection probability and the attribution of a specific behaviour to others was powerful enough to remove one of the highest variables of risk of severe form of the disease: age (Liao et al., 2020). Indeed, we found no association between our clusters and age, or with retired people. This result was also reported by previous study in mainland China (Y. Huang and Zhao, 2020), Hong-Kong (E. Y. Y. Chan et al., 2020) and in an international survey (Clark et al., 2020). Decisions of this group to less apply the lockdown rules could also refer to social and moral decision-making under uncertainty and cooperating behaviours, which were already presented as levers to increase people implication and acceptance (Bavel et al., 2020). For this third cluster, we can assume that they had a decreased lockdown respect for two main reasons. First, since they perceived negative outcomes on others as of low probability, reducing the relevance to strictly respect the measures (Garcia et al., 2018; Gino et al., 2016). Secondly, since they perceived the measures' respect by others as higher, they estimated as less relevant to respect them themselves, corresponding to a large range of research in Psychology and Neurosciences (Strang and Park, 2016).

Limitations. Several limitations in our study have to be addressed. First, the used sample was unbalanced and involved an over- 
Table 3 Estimated probabilities to be in one of the three generated clusters.

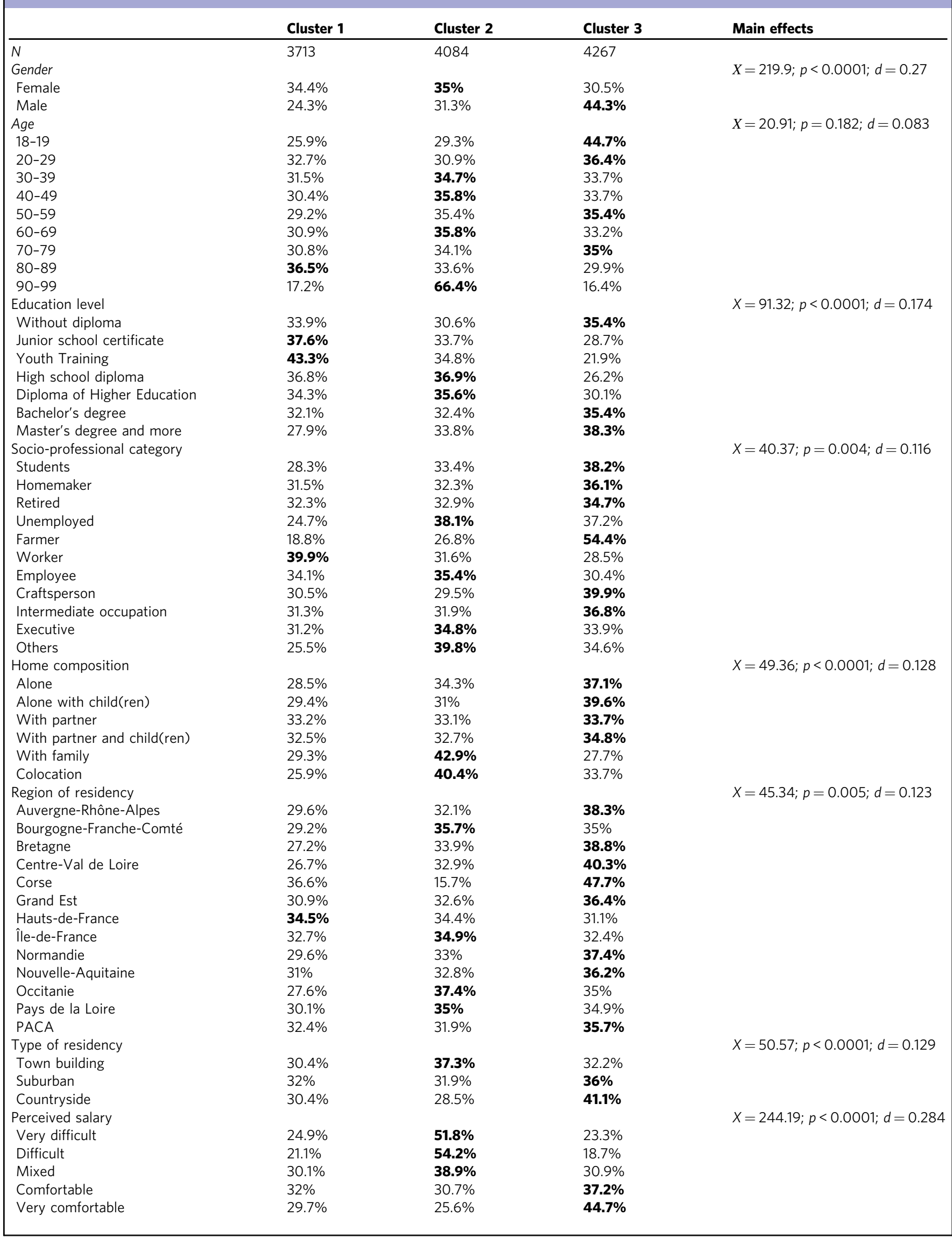


Table 3 (continued)

\begin{tabular}{|c|c|c|c|c|}
\hline & Cluster 1 & Cluster 2 & Cluster 3 & Main effects \\
\hline Change of residence & & & & $X=13.57 ; p=0.035 ; d=0.067$ \\
\hline No, without reception & $31.2 \%$ & $34.7 \%$ & $34.1 \%$ & \\
\hline No, with reception & $31.1 \%$ & $32.9 \%$ & $35.9 \%$ & \\
\hline Yes, to close relations & $30.4 \%$ & $31.9 \%$ & $37.7 \%$ & \\
\hline Yes, to second home & $28.6 \%$ & $28 \%$ & $43.3 \%$ & \\
\hline
\end{tabular}

representation of the persons with high diploma and executives. This issue was mainly solved using partial models (logistic and multinomial regressions) that taken into account all other variables involved in the model to control for their effects. Second, we did not obtain data during the first lockdown week. These data probably would have represented the most anxiogenic and most uncertain time of the lockdown. Third, we did not record if participants or their close relations were tested as positive to the Covid-19. However, our objective was to identify the representations associated to the lockdown and not to obtain medical information. In addition, recording such an information would have required an approval by an ethical board, which would have led to not obtain data during a large part (and potentially the entirety) of the lockdown.

\section{Conclusion}

To sum up, respect of the lockdown measures was mainly altered by an unfavourable living environment (referring to social and economic inequity), a high feeling of fear associated with a lack of trust towards Governmental measures, and a low risk perception which lean on the feeling that others respected the measures. Based on our findings, we confirm observations suggesting that compliance is more impacted by situation perception than preexisting dispositions (Zajenkowski et al., 2020). Governments will have to broadcast skilled speeches (Everett et al., 2020) to increase measures acceptance by improving trust (Fancourt et al., 2020), limiting fear and increasing cooperative behaviours. Reaching such an objective is crucial and could contribute to decrease the need of future lockdown (López and Rodó, 2020).

\section{Data availability}

The dataset generated and analysed during the current study is available from the corresponding author on reasonable request.

\section{Code availability}

The codes generated to analyse the dataset are available from the corresponding author on reasonable request.

Received: 31 August 2020; Accepted: 26 January 2021;

Published online: 19 March 2021

\section{References}

Ahorsu DK, Lin C-Y, Imani V, Saffari M, Griffiths MD, Pakpour AH (2020) The Fear of COVID-19 Scale: development and initial validation. Int J Ment Health Addict. https://doi.org/10.1007/s11469-020-00270-8

Aslam F, Awan TM, Syed JH et al. (2020) Sentiments and emotions evoked by news headlines of coronavirus disease (COVID-19) outbreak. Human Soc Sci Commun 7(1):23. https://doi.org/10.1057/s41599-020-0523-3

Ball G, Hall D (1965) ISODATA, a novel method of data analysis and pattern classification. Stanford Research Institute, Menlo Park

Bavel JJV, Baicker K, Boggio PS et al. (2020) Using social and behavioural science to support COVID-19 pandemic response. Nat Hum Behav 4(5):460-471. https://doi.org/10.1038/s41562-020-0884-z

Beale E Cluster analysis. Scientific Control Systems, London
Bi Q, Wu Y, Mei S, Ye C, Zou X, Zhang Z, Liu X, Wei L, Truelove SA, Zhang T, Gao W, Cheng C, Tang X, Wu X, Wu Y, Sun B, Huang S, Sun Y, Zhang J, ... Feng $\mathrm{T}$ (2020) Epidemiology and transmission of COVID-19 in 391 cases and 1286 of their close contacts in Shenzhen, China: A retrospective cohort study. Lancet Infect Dis 20(8):911-919. https://doi.org/10.1016/S1473-3099(20)30287-5

Bish A, Michie S (2010) Demographic and attitudinal determinants of protective behaviours during a pandemic: a review. Br J Health Psychol 15(4):797-824. https://doi.org/10.1348/135910710X485826

Bodas M, Peleg K (2020) Self-isolation compliance in the COVID-19 Era influenced by compensation: findings from a recent survey In Israel: public attitudes toward the COVID-19 outbreak and self-isolation: a cross sectional study of the adult population of Israel. Health Aff 39(6):936-941. https://doi org/10.1377/hlthaff.2020.00382

Bolarinwa OA, Olagunju O, Babalola T, Saeed BQ (2020) Socio-demographic predictors of adherence to 2019 coronavirus prescribed recommendations and lockdown psychological impacts: Perspectives of Nigerian social media users. J Public Health Res 9(4):1864. https://doi.org/10.4081/jphr.2020.1864

Brand M, Recknor EC, Grabenhorst F et al. (2007) Decisions under ambiguity and decisions under risk: correlations with executive functions and comparisons of two different gambling tasks with implicit and explicit rules. J Clin Exp Neuropsychol 29(1):86-99. https://doi.org/10.1080/13803390500507196

Brooks SK, Webster RK, Smith LE et al. (2020) The psychological impact of quarantine and how to reduce it: rapid review of the evidence. Lancet 395 (10227):912-920. https://doi.org/10.1016/S0140-6736(20)30460-8

Calinski T, Harabasz J (1974) A dendrite method for cluster analysis. Commun Stat -Theory Methods 3(1):1-27. https://doi.org/10.1080/03610927408827101

Carlucci L, D’Ambrosio I, Balsamo M (2020) Demographic and attitudinal factors of adherence to quarantine guidelines during COVID-19: the Italian model Front Psychol 11:559288. https://doi.org/10.3389/fpsyg.2020.559288

Cauchemez S, Kiem CT, Paireau J et al. (2020) Lockdown impact on COVID-19 epidemics in regions across metropolitan France. Lancet 396(10257):1068-1069. https://doi.org/10.1016/S0140-6736(20)32034-1

Chan EYY, Huang Z, Lo ESK et al. (2020) Sociodemographic predictors of health risk perception, attitude and behavior practices associated with healthemergency disaster risk management for biological hazards: the case of COVID-19 pandemic in Hong Kong, SAR China. Int J Environ Res Public Health 17(11):3869. https://doi.org/10.3390/ijerph17113869

Chan HF, Skali A, Savage DA et al. (2020) Risk attitudes and human mobility during the COVID-19 pandemic. Sci Rep 10(1):19931. https://doi.org/ 10.1038/s41598-020-76763-2

Charrad M, Ghazzali N, Boiteau V, Niknafs A (2014) NbClust: an R package for determining the relevant number of clusters in a data set. J Stat Softw 61(6) https://doi.org/10.18637/jss.v061.i06

Chinazzi M, Davis JT, Ajelli M, Gioannini C, Litvinova M, Merler S, Pastore y Piontti A, Mu K, Rossi L, Sun K, Viboud C, Xiong X, Yu H, Halloran ME, Longini IM, Vespignani A (2020) The effect of travel restrictions on the spread of the 2019 novel coronavirus (COVID-19) outbreak. Science eaba9757. https://doi.org/10.1126/science.aba9757

Chu DK, Akl EA, Duda S et al. (2020) Physical distancing, face masks, and eye protection to prevent person-to-person transmission of SARS-CoV-2 and COVID-19: a systematic review and meta-analysis. The Lancet 395 (10242):1973-1987. https://doi.org/10.1016/S0140-6736(20)31142-9

Chung RY-N, Dong D, Li MM (2020) Socioeconomic gradient in health and the covid-19 outbreak. BMJ m1329. https://doi.org/10.1136/bmj.m1329

Clark C, Davila A, Regis M et al. (2020) Predictors of COVID-19 voluntary compliance behaviors: an international investigation. Glob Transit 2:76-82. https://doi.org/10.1016/j.glt.2020.06.003

Cohen J (2013) Statistical power analysis for the behavioral sciences. Taylor and Francis

Davies DL, Bouldin DW (1979) A cluster separation measure. IEEE Trans Pattern Anal Mach Intell PAMI-1(2), 224-227 https://doi.org/10.1109/TPAMI.1979.4766909

DiGiovanni C, Conley J, Chiu D et al. (2004) Factors influencing compliance with quarantine in Toronto during the 2003 SARS Outbreak. Biosecur Bioterror 2 (4):265-272. https://doi.org/10.1089/bsp.2004.2.265

Duan T, Jiang H, Deng X et al. (2020) Government intervention, risk perception, and the adoption of protective action recommendations: evidence from the COVID- 
19 prevention and control experience of China. Int J Environ Res Public Health 17(10):3387. https://doi.org/10.3390/ijerph17103387

Duda R, Hart P (1973) Pattern classification and scene analysis. John Wiley \& Sons, New York

Dunn JC (1974) Well-separated clusters and optimal fuzzy partitions. J Cybern 4 (1):95-104

Duque-Calvache R, Torrado JM, Mesa-Pedrazas Á (2020) Lockdown and adaptation: residential mobility in Spain during the COVID-19 crisis. Eur Soc 0 (0):1-18. https://doi.org/10.1080/14616696.2020.1836386

Everett JAC, Colombatto C, Chituc V, Brady WJ, Crockett M (2020) The effectiveness of moral messages on public health behavioral intentions during the COVID-19 pandemic [Preprint]. PsyArXiv. https://doi.org/10.31234/osf.io/9yqs8

Fancourt D, Steptoe A, Wright L (2020) The Cummings effect: politics, trust, and behaviours during the COVID-19 pandemic. Lancet 396(10249):464-465. https://doi.org/10.1016/S0140-6736(20)31690-1

Friedman HP, Rubin J (1967) On some invariant criteria for grouping data. J Am Stat Assoc 62(320):1159-1178. https://doi.org/10.1080/01621459.1967.10500923

Garcia T, Massoni S, Villeval MC (2018) Ambiguity and excuse-driven behavior in charitable giving. SSRN Electron J. https://doi.org/10.2139/ssrn.3283773

Gino F, Norton MI, Weber RA (2016) Motivated Bayesians: feeling moral while acting egoistically. J Econ Perspect 30(3):189-212. https://doi.org/10.1257/ jep.30.3.189

Habersaat KB, Betsch C, Danchin M, Sunstein CR, Böhm R, Falk A, Brewer NT, Omer SB, Scherzer M, Sah S, Fischer EF, Scheel AE, Fancourt D, Kitayama S, Dubé E, Leask J, Dutta M, MacDonald NE, Temkina A, ... Butler R (2020) Ten considerations for effectively managing the COVID-19 transition. Nat Hum Behav. https://doi.org/10.1038/s41562-020-0906-x

Halkidi M, Vazirgiannis M (2001) Clustering validity assessment: finding the optimal partitioning of a data set. In: Proceedings 2001 IEEE international conference on data mining, IEEE, p 187-194

Halkidi M, Vazirgiannis M, Batistakis Y (2000) Quality scheme assessment in the clustering process. In: Zighed DA, Komorowski J, Żytkow J (eds) Principles of data mining and knowledge discovery, vol 1910. Springer, Berlin, Heidelberg, p 265-276

Harper CA, Satchell LP, Fido D, Latzman RD (2020) Functional fear predicts public health compliance in the COVID-19 pandemic. Int J Ment Health Addict. https://doi.org/10.1007/s11469-020-00281-5

Hartigan J (1975) Clustering algorithms. John Wiley \& Sons, New York

Hartley CA, Phelps EA (2012) Anxiety and decision-making. Biol Psychiatry 72 (2):113-118. https://doi.org/10.1016/j.biopsych.2011.12.027

Heilman RM, Crişan LG, Houser D et al. (2010) Emotion regulation and decision making under risk and uncertainty. Emotion 10(2):257-265. https://doi.org/ 10.1037/a0018489

Holuka C, Merz MP, Fernandes SB et al. (2020) The COVID-19 pandemic: does our early life environment, life trajectory and socioeconomic status determine disease susceptibility and severity? Int J Mol Sci 21(14):5094. https://doi.org/ 10.3390/ijms21145094

Huang F, Ding H, Liu Z et al. (2020) How fear and collectivism influence public's preventive intention towards COVID-19 infection: a study based on big data from the social media. BMC Public Health 20(1):1707. https://doi.org/ 10.1186/s12889-020-09674-6

Huang Y, Zhao N (2020) Generalized anxiety disorder, depressive symptoms and sleep quality during COVID-19 epidemic in China: a web-based cross-sectional survey. Psychiatry Res 288:112954. https://doi.org/10.1016/j.psychres.2020.112954

Hubert LJ, Levin JR (1976) A general statistical framework for assessing categorical clustering in free recall. Psychol Bull 83(6):1072-1080. https://doi.org/ 10.1037/0033-2909.83.6.1072

INSEE (2020) Population présente sur le territoire avant et après le début du confinement-Premiers résultats. INSEE

Koh D (2020) Occupational risks for COVID-19 infection. Occup Med 70(1):3-5. https://doi.org/10.1093/occmed/kqaa036

Krzanowski WJ, Lai YT (1988) A criterion for determining the number of groups in a data set using sum-of-squares clustering. Biometrics 44(1):23. https://doi. org $/ 10.2307 / 2531893$

Lewnard JA, Lo NC (2020) Scientific and ethical basis for social-distancing interventions against COVID-19. Lancet Infect Dis 20(6):631-633. https://doi.org/ 10.1016/S1473-3099(20)30190-0

Liao J, Fan S, Chen J et al. (2020) Epidemiological and clinical characteristics of COVID-19 in adolescents and young adults Innovation (NY) 1(1):100001. https://doi.org/10.1016/j.xinn.2020.04.001

López L, Rodó X (2020) The end of social confinement and COVID-19 re-emergence risk. Nat Hum Behav 4(7):746-755. https://doi.org/10.1038/s41562020-0908-8

Marriott FHC (1971) Practical problems in a method of cluster analysis. Biometrics 27(3):501. https://doi.org/10.2307/2528592

Martarelli CS, Wolff W (2020) Too bored to bother? Boredom as a potential threat to the efficacy of pandemic containment measures. Human Soc Sci Commun 7(1):28. https://doi.org/10.1057/s41599-020-0512-6
Maunder R, Hunter J, Vincent L et al. (2003) The immediate psychological and occupational impact of the 2003 SARS outbreak in a teaching hospital. Can Med Assocn J 168(10):1245-1251

McClain J, Rao V (1975) CLUSTISZ: a program to test for the quality of clustering of a set of objects. J Market Res 12(4):456-460

Milligan GW (1980) An examination of the effect of six types of error perturbation on fifteen clustering algorithms. Psychometrika 45(3):325-342. https://doi. org/10.1007/BF02293907

Milligan GW, Cooper MC (1985) An examination of procedures for determining the number of clusters in a data set. Psychometrika 50(2):159-179. https:// doi.org/10.1007/BF02294245

Murphy K, Williamson H, Sargeant E, McCarthy M (2020) Why people comply with COVID-19 social distancing restrictions: Self-interest or duty? Austral $\mathrm{N}$ Z J Criminol 000486582095448. https://doi.org/10.1177/0004865820954484

Nicola M, Alsafi Z, Sohrabi C et al. (2020) The socio-economic implications of the coronavirus pandemic (COVID-19): a review. Int J Surg 78:185-193. https:// doi.org/10.1016/j.ijsu.2020.04.018

Nivette A, Ribeaud D, Murray A et al. (2021) Non-compliance with COVID-19related public health measures among young adults in Switzerland: insights from a longitudinal cohort study. Soc Sci Med 268:113370. https://doi.org/ 10.1016/j.socscimed.2020.113370

Patel JA, Nielsen FBH, Badiani AA et al. (2020) Poverty, inequality and COVID-19: The forgotten vulnerable. Public Health 183:110-111. https://doi.org/ 10.1016/j.puhe.2020.05.006

Pullano G, Valdano E, Scarpa N et al. (2020) Evaluating the effect of demographic factors, socioeconomic factors, and risk aversion on mobility during the COVID-19 epidemic in France under lockdown: a population-based study. Lancet Digit Health 2(12):e638-e649. https://doi.org/10.1016/S2589-7500(20) 30243-0

R Core Team (2013) R: A language and environment for statistical computing. R Foundation for Statistical Computing. http://www.R-project.org/

Ratkowsky D, Lance G (1978) A criterion for determining the number of groups in a classification. Australian Computer Journal 10(3):115-117

Reintjes R, Das E, Klemm C et al. (2016) "Pandemic Public Health Paradox": time series analysis of the 2009/10 Influenza A/H1N1 epidemiology, media attention, risk perception and public reactions in 5 european countries. PLoS ONE 11(3):e0151258. https://doi.org/10.1371/journal.pone.0151258

Reynolds B, Seeger WM (2005) Crisis and emergency risk communication as an integrative model. J Health Commun 10(1):43-55. https://doi.org/10.1080/ 10810730590904571

Rousseeuw PJ (1987) Silhouettes: a graphical aid to the interpretation and validation of cluster analysis. J Comput Appl Math 20:53-65. https://doi.org/ 10.1016/0377-0427(87)90125-7

Sarle W (1983) SAS Technical Report A-108. Cubic clustering criterion. SAS Institute Inc, Cary, $\mathrm{NC}$

Sawilowsky SS (2009) New effect size rules of thumb. J Mod Appl Stat Methods 8 (2):597-599. https://doi.org/10.22237/jmasm/1257035100

Scott A, Symons M (1971) Clustering methods based on likelihood ratio criteria. Biometrics 27(2):387-397. https://doi.org/10.2307/2529003

Serrano-Ripoll MJ, Meneses-Echavez JF, Ricci-Cabello I et al. (2020) Impact of viral epidemic outbreaks on mental health of healthcare workers: A rapid systematic review and meta-analysis. J Affect Disord 277:347-357. https://doi.org/10.1016/ j.jad.2020.08.034

Sharot T (2011) The optimism bias. Curr Biol 21(23):R941-R945. https://doi.org/ 10.1016/j.cub.2011.10.030

Sheikh A, Sheikh Z, Sheikh A (2020) Novel approaches to estimate compliance with lockdown measures in the COVID-19 pandemic. J Glob Health 10 (1):010348. https://doi.org/10.7189/jogh.10.010348

Shinan-Altman S, Levkovich I (2020) COVID-19 precautionary behavior: the Israeli case in the initial stage of the outbreak. BMC Public Health 20(1):1718 https://doi.org/10.1186/s12889-020-09818-8

Storopoli J, Braga da Silva Neto WL, Mesch GS (2020) Confidence in social institutions, perceived vulnerability and the adoption of recommended protective behaviors in Brazil during the COVID-19 pandemic. Soc Sci Med (1982), 113477. https://doi.org/10.1016/j.socscimed.2020.113477

Strang S, Park SQ (2016) Human cooperation and its underlying mechanisms. In: Wöhr M, Krach S (eds) Social behavior from rodents to humans, vol 30 Springer International Publishing, p 223-239

Taylor MR, Agho KE, Stevens GJ et al. (2008) Factors influencing psychological distress during a disease epidemic: Data from Australia's first outbreak of equine influenza. BMC Public Health 8(1):347. https://doi.org/10.1186/14712458-8-347

Tian H, Liu Y, Li Y et al. (2020) An investigation of transmission control measures during the first 50 days of the COVID-19 epidemic in China. Science 368 (6491):638-642. https://doi.org/10.1126/science.abb6105

Tibshirani R, Walther G, Hastie T (2001) Estimating the number of clusters in a data set via the gap statistic. J R Stat Soc Ser B 63(2):411-423. https://doi.org/ $10.1111 / 1467-9868.00293$ 
van der Pligt J (1996) Risk perception and self-protective behavior. Eur Psychol 1 (1):34-43. https://doi.org/10.1027/1016-9040.1.1.34

Wells CR, Sah P, Moghadas SM et al. (2020) Impact of international travel and border control measures on the global spread of the novel 2019 coronavirus outbreak. Proc Natl Acad Sci USA 117(13):7504-7509. https://doi.org/ 10.1073/pnas.2002616117

Wise T, Zbozinek TD, Michelini G et al. (2020) Changes in risk perception and protective behavior during the first week of the COVID-19 pandemic in the United States. R Soc Open Sci 7(9):200742. https://doi.org/10.1098/rsos.200742

Witte K, Allen M (2000) A meta-analysis of fear appeals: implications for effective public health campaigns. Health Educ Behav 27(5):591-615. https://doi.org/ $10.1177 / 109019810002700506$

Xu J, Peng Z (2015) People at risk of influenza pandemics: the evolution of perception and behavior. PLoS ONE 10(12):e0144868. https://doi.org/10.1371/ journal.pone.0144868

Yang Q, Zhao D, Wu Y et al. (2018) Differentiating the influence of incidental anger and fear on risk decision-making. Physiol Behav 184:179-188. https:// doi.org/10.1016/j.physbeh.2017.11.028

Zajenkowski M, Jonason PK, Leniarska M et al. (2020) Who complies with the restrictions to reduce the spread of COVID-19?: Personality and perceptions of the COVID-19 situation. Personal Individ Differ 166:110199. https://doi. org/10.1016/j.paid.2020.110199

Zhang C, Chen C, Shen W et al. (2020) Impact of population movement on the spread of 2019-nCoV in China. Emerg Microbes Infect 9(1):988-990. https:// doi.org/10.1080/22221751.2020.1760143

Zhang R, Li Y, Zhang AL et al. (2020) Identifying airborne transmission as the dominant route for the spread of COVID-19. Proc Natl Acad Sci USA 117 (26):14857-14863. https://doi.org/10.1073/pnas.2009637117

\section{Acknowledgements}

The authors wish to thank Anita Augereau and Valery Lansiaux for their helpful support and their suggestions. This study was not supported by a specific grant.

\section{Author contributions}

Authors participated to the conception and design of the work, acquisition, analysis and interpretation of the data, and have drafted the manuscript.

\section{Competing interests}

The authors declare no competing interests.

\section{Additional information}

Supplementary information The online version contains supplementary material available at https://doi.org/10.1057/s41599-021-00749-2.

Correspondence and requests for materials should be addressed to C.A.-C.

Reprints and permission information is available at http://www.nature.com/reprints

Publisher's note Springer Nature remains neutral with regard to jurisdictional claims in published maps and institutional affiliations.

cc (i) Open Access This article is licensed under a Creative Common Attribution 4.0 International License, which permits use, sharing adaptation, distribution and reproduction in any medium or format, as long as you give appropriate credit to the original author(s) and the source, provide a link to the Creative Commons license, and indicate if changes were made. The images or other third party material in this article are included in the article's Creative Commons license, unless indicated otherwise in a credit line to the material. If material is not included in the article's Creative Commons license and your intended use is not permitted by statutory regulation or exceeds the permitted use, you will need to obtain permission directly from the copyright holder. To view a copy of this license, visit http://creativecommons.org/ licenses/by/4.0/.

(c) The Author(s) 2021 